\title{
Altered gene expression profiles of NIH3T3 cells regulated by human lung cancer associated gene $C T 120$
}

\author{
Xiang Huo HE*, Jin Jun LI*, Yi Hu XIE, Yun Tian TANG, Gen Fu YAO, Wen Xin QIN, Da Fang WAN**, \\ Jian Ren GU
}

State Key Laboratory of Oncogenes and Related Genes, Shanghai Cancer Institute, Shanghai Jiao-Tong University Medical School, 2200Ln/25, Xie Tu Road, Shanghai 200032, China

\begin{abstract}
CT120, a novel membrane-associated gene implicated in lung carcinogenesis, was previously identified from chromosome 17p13.3 locus, a hot mutation spot involved in human malignancies. In the present study, we further determined that CT120 ectopic expression could promote cell proliferation activity of NIH3T3 cells using MTS assay, and monitored the downstream effects of CT120 in NIH3T3 cells with Atlas mouse cDNA expression arrays. Among 588 known genes, 133 genes were found to be upregulated or downregulated by CT120. Two major signaling pathways involved in cell proliferation, cell survival and anti-apoptosis were overexpressed and activated in response to CT120: One is the Raf/MEK/Erk signal cascades and the other is the PI3K/Akt signal cascades, suggesting that CT120 might contribute, at least in part, to the constitutively activation of Erk and Akt in human lung caner cells. In addition, some tumor metastasis associated genes cathepsin B, cathepsin D, cathepsin L, MMP-2/TIMP-2 were also upregulated by CT120, upon which CT120 might be involved in tumor invasiveness and metastasis. In addition, CT120 might play an important role in tumor progression through modulating the expression of some candidate "Lung Tumor Progression" genes including $B-R a f$, Rab-2, $B A X, B A G-1, Y B-1$, and $C d c 42$.
\end{abstract}

Keywords: CT120, cell proliferation, lung, gene expression, metastasis.

\section{INTRODUCTION}

The 2000 estimate represents as increase of around $22 \%$ in incidence and mortality of human malignancies all over the world. Whether considered in terms of incidence or mortality, lung cancer is the main cancer because of the high case mortality [1]. Lung cancer cells often show chromosomal abnormality including numerical and/or structural changes $[2,3]$, resulting in oncogene activation and/or tumor suppressor gene inactivation, which is required to support lung carcinogenesis [4-7]. Identification and characterization of various tumor-related genes that are genetically or epigenetically altered in human lung cancer will deepen our understanding of lung tumorigenesis. CT120 was previously isolated from chromosome $17 \mathrm{p} 13.3$ locus in our laboratory and was identified as a potential 7 trans-membrane $\mathrm{G}$ protein-coupled receptor. CT120 was

\footnotetext{
*These authors contributed equally to this work

** Correspondence: Da Fang WAN

Tel \& Fax: 86-21-64177401

E-mail: nlorg@public.sta.net.cn
}

expressed remarkably higher in lung cancers than in noncancerous tissues as well as normal lung tissues, and it can increase the colony formation efficiency of NIH3T3 cells and promote the proliferation of human lung adenocarcinoma A549 cells in vitro and in vivo, suggesting that CT120 may involve in lung carcinogenesis [8, 9].

The expression profile or "transcriptome", a collection of genes that are transcribed from genomic DNA, is a major determinant of cellular phenotype and function. Changes in the gene expression patterns can provide clues about cellular functions and biochemical pathway in cells. Methods of comparing global gene expression profile varies in different biological samples have been developed, such as differential display PCR (DD-PCR) [10], serial analysis of gene expression (SAGE) [11], and cDNA microarray [12]. Recently, the use of microarray to profile gene expression on a global level has recently received a great deal of attention. Microarray technology facilitates a more complete and inclusive experimental approach by which alterations in the transcript level of entire genomes can be simultaneously assayed in response to a variety of stimuli or cells treated with growth factors in order to explore downstream 
target genes or downstream signaling pathways [13-15].

This report is designed to further investigate the effect of CT120 ectopic expression on cell growth of NIH3T3 cells, and focused on the use of cDNA microarray technology as a means of identifying downstream signaling pathways regulated by human lung cancer associated gene CT120.

\section{MATERIALS AND METHODS}

\section{Plasmid construction}

To construct eukaryotic expression plasmid, the ORF of CT120 was amplified with the following forward primer: 5'ATGCTGCTGACGCTGGCCGG-3' and reverse primer: 5'TTAGCCATCCTTTTTGGCTT-3'. The amplified products were subcloned into eukaryotic expression vector pcDNA4/HisMax TOPO-TA (Invitrogen) and designated as HisMax-CT120, which encodes $6 \times$ His-tagged CT120 fusion protein. The identity of CT120 was confirmed by sequencing.

\section{Cell culture and transfection}

Mouse fibroblast NIH3T3 cells were grown under $5 \% \mathrm{CO}_{2}$ at $37^{\circ} \mathrm{C}$ in Dulbecco's modified Eagle medium (DMEM) supplemented with $10 \%$ fetal bovine serum. Transfection of cells was performed with the LIPOFECTAME reagent by the manufacturer's instructions (Gibco BRL). NIH3T3 cells were seeded at $1 \times 10^{5} /$ well in $6-$ well plates and transfected with plasmids HisMax-CT120 and pcDNA/Hix-Max vector $24 \mathrm{~h}$ later. After $48 \mathrm{~h}$, the transfected cells were screened with $100 \mu \mathrm{g} / \mathrm{ml}$ zeocin reagent (Invitrogen). Two weeks (14 d) later, colonies of transfected cells were picked out and cultured to expansion. Expression of CT120 in transfected NIH3T3 cells was detected by Western blotting with $6 \times$ HisG monoclonal antibody (Invitrogen).

\section{Cell proliferation activity assay}

Cell proliferation assays of NIH3T3 cells transfected with CT120 and pcDNA3.1/HA2 (Clontech) were conducted with CellTiter 96 AQueous One Solution Cell Proliferation Assay kit (Promega) according to the Manufacturer's manual. Briefly, cells were plated into flat-bottomed 96 -well plates at the density of $2 \times 10^{3}$ cells /well and cultured for $7 \mathrm{~d}$ (each day as a time point). $20 \mu$ l One Solution Reagent MTS was pipetted into each well of the 96-well assay plate containing $100 \mu \mathrm{l}$ of fresh culture medium; Then the plate was incubated for $2 \mathrm{~h}$ at $37^{\circ} \mathrm{C}$ in a humidified, $5 \% \mathrm{CO}_{2}$ atmosphere. The absorbance at $490 \mathrm{~nm}$ was recorded using a Model-550 ELISA plate reader (Bio-Rad). A growth curve with the absorbance of the MTS assay was directly correlated with the number of metabolically active cells.

\section{RNA preparation and cDNA probe synthesis}

Total RNA of NIH3T3 cells transfected with CT120 and pcDNA3.1/ HA2 was extracted using Trizol reagent (Invitrogen), then treated with RNase-free DNase I to eliminate potential genomic contamination. $\left[\alpha_{-}{ }^{32} \mathrm{P}\right] \mathrm{dATP}(3,000 \mathrm{Ci} / \mathrm{mM}, 10 \mu \mathrm{Ci} / \mu \mathrm{l})($ Amersham Biosciences) labeled probes were synthesized from $5 \mu \mathrm{g}$ of total RNA with Atlas Pure Total RNA Labeling System (Qiagen). Briefly, $5 \mu \mathrm{g}$ total RNA and $1 \mu \mathrm{l} \mathrm{CDS}$ primer mix were incubated at $70^{\circ} \mathrm{C}$ for $2 \mathrm{~min}$, then $5 \times$ reaction buffer, $1 \mu 110 \times \mathrm{dNTP} \operatorname{mix}, 3.5 \mu 1\left[\alpha_{-}{ }^{32} \mathrm{P}\right]$ dATP, $0.5 \mu 1100 \mathrm{mM}$ dithiothreitol and $1 \mu \mathrm{l}$ MMLV reverse tran- scriptase (Promega) were added and the mixture was incubated at $50{ }^{\circ} \mathrm{C}$ for $25 \mathrm{~min}$. After incubation, the reaction was stopped by adding $1 \mu 1$ of $10 \times$ termination mix and placed on ice. The ${ }^{32} \mathrm{P}$-labeled cDNA probes were purified with NucleoSpin Extraction Column (Qiagen) according to the manufacturer's protocols .

\section{Hybridization and analysis of ATLAS mouse cDNA expres- sion array}

To investigate the differential gene expression profiles induced by novel gene CT120, cDNA microarray was performed with mouse ATLAS cDNA expression Arrays (BD Bioscieneces). The membranes were prehybridized at $68^{\circ} \mathrm{C}$ for $30 \mathrm{~min}$ in $10 \mu \mathrm{l}$ ExpressHyb buffer with $5 \mu \mathrm{g}$ denatured, sheared salmon testes DNA. Hybridization was performed at $68{ }^{\circ} \mathrm{C}$ overnight with continuous rotation. Then the membranes were washed twice with $2 \times$ SSC and $1 \%$ SDS at $68{ }^{\circ} \mathrm{C}$ for $30 \mathrm{~min}$, and twice with $0.1 \times \mathrm{SSC}$ and $0.5 \% \mathrm{SDS}$ at $68^{\circ} \mathrm{C}$ for $30 \mathrm{~min}$. The filters were autophotographed on X-ray film at $-70^{\circ} \mathrm{C}$. Signals developed on the X-ray films were submitted to quantitative analysis using QuantArray imaging software (Packard Bioscience Inc.) specialized for the high-density array analysis and each hybridization spot was quantified against the internal control.

\section{Reverse transcriptase-PCR (RT-PCR)}

To confirm the hybridization result of ATLAS cDNA expression array, the expression of four randomly selected genes were investigated using semi-quantitative RT-PCR. One microgram of total RNA from CT120 or vector transfected NIH3T3 cells was reverse-transcribed using Superscript II RNase-Reverse Transcriptase (Gibco$\mathrm{BRL}$ ) with an oligo (dT) primer respectively. One microliter of the reaction mixture was used as template for PCR amplification in a total of $25 \mu 1$ volume with Taq polymerase (Promega). PCR conditions were $95^{\circ} \mathrm{C}$ for $3 \mathrm{~min}$, followed by 30 cycles at $94^{\circ} \mathrm{C}$ for $30 \mathrm{~s}$, $60^{\circ} \mathrm{C}$ for $30 \mathrm{~s}, 72^{\circ} \mathrm{C}$ for $45 \mathrm{~s}$, and $72^{\circ} \mathrm{C}$ for $5 \mathrm{~min}$. For standardization and quantification, $\beta$-actin was used as an internal control. The primer sequences and products of selected genes for RT-PCR were summarized in Tab. 1.

\section{Immunoblotting assay}

To prepare cell extracts, NIH3T3 cells transfected with CT120 and vector were washed twice with ice cold PBS and lysed with lysis buffer (supplied in Luciferase Detection Kit, Roche) for 15 min on ice. The whole cell lysates were centrifuged for $10 \mathrm{~min}$, then were resolved by SDS-PAGE and transferred to PROTRAN Nitrocellular Transfer membranes (Bio-Rad). After transfer, the filters were blocked with PBS-T containing 5\% non-fat dry milk for $1 \mathrm{~h}$. The membranes were subsequently incubated with rabbit anti-PI3K p85, goat antiAkt1/2 polyclonal antibody, goat anti-p-MEK1/2, rabbit anti-Erk1, rabbit anti-Erk2, goat anti-p-Erk1/2 (Santa Cruz Biotechnology), rabbit anti-phospho-Akt ser473 polyclonal antibody (Cell Signaling Technology) overnight at $4{ }^{\circ} \mathrm{C}$. Then the membranes were washed three times with PBS-T before incubating with horseradish peroxidase-conjugated $\operatorname{IgG}$ (Sigma) for $1 \mathrm{~h}$. The bands were detected with SuperSignal West Femto Maximum sensitivity substrate (Pierce).

\section{Immunocytochemistry assay}

NIH3T3 cells stably transfected with CT120 and vector were grown on glass coverslips in 6-well plates. Twenty-four hours later, cells were washed twice in cold PBS, fixed with freshly prepared $10 \%$ PBS-buffered formaldehyde for $30 \mathrm{~min}$ and permeabilized with 
Tab. 1 Primers and Products for RT-PCR

\begin{tabular}{|c|c|c|c|c|}
\hline Gene & GenBank No. & Orientation & Primer sequence & Product size (bp) \\
\hline \multirow[t]{2}{*}{$P I 3 K$} & M60651 & $\mathrm{F}$ & 5'-GGAGGTGAAGCTGAGAGTGG-3' & 210 \\
\hline & & $\mathrm{R}$ & 5'-GTCCATCTGTCCTCCATCA-3' & \\
\hline \multirow[t]{2}{*}{ Akt } & M94335 & $\mathrm{F}$ & 5'-TCAAGATAACGGACTTCGGG-3' & 389 \\
\hline & & $\mathrm{R}$ & 5'-ATACACATCCTGCCACACGA-3' & \\
\hline \multirow[t]{2}{*}{$M E K 1$} & L02526 & $\mathrm{F}$ & 5'-GCCAGCATCTGAGCCTTTAG-3' & 300 \\
\hline & & $\mathrm{R}$ & 5'-TAAGAACGACCACCCAGGTC-3' & \\
\hline \multirow[t]{2}{*}{ ITGA6 } & X69902 & $\mathrm{F}$ & 5'-TACCTAGGCTTTTCGCTGGA-3' & 293 \\
\hline & & $\mathrm{R}$ & 5'-TAGACGTAAACTGCACCCCC-3' & \\
\hline
\end{tabular}

$0.2 \%$ Triton X-100 in PBS for 10 min. Samples were reacted with the above antibodies (diluted 1:50) in PBS for $1 \mathrm{~h}$, followed by the detection with EnVision System (DAKO). Finally, 0.5\% DAB- $\mathrm{H}_{2} \mathrm{O}_{2}$ was used as a chromogen to incubate slides for $30 \mathrm{~min}$ for visualization. Slides were counterstained with Mayer's hematoxylin and mounted. Microscope and image analysis were performed with Axioskop 2 (Carl Zeiss, Germany).

\section{RESULTS}

\section{Ectopic expression of CT120 can promote NIH3T3 cell proliferation in vitro}

The regulatory effects of CT120 on NIH3T3 cells were investigated with cell proliferation ability assay. The stable transfectants of NIH3T3 cells expressing CT120 were established by zeocin reagent (BD Biosciences) selection and the expression of His-tagged CT120 in NIH3T3 stable transfectants were examined using immunoblotting analysis with $6 \times$ HisG monoclonal antibody (Fig. 1). MTS assays showed that CT120 expression remarkably increase the cell growth at the $3 \mathrm{~d}$ and persisted to the $7 \mathrm{~d}$ when compared with vector control $(P<0.01)$ (Fig. 1).

\section{Hybridization of ATLAS mouse cDNA gene expression array with cDNA probes prepared from NIH3T3 cells stably transfected with $C T 120$ and vector}

To determine the downstream effects of novel gene CT120, we performed ATLAS mouse cDNA microarray expression analysis on the NIH3T3 cells stably transfected with $C T 120$ and vector. The Atlas mouse cDNA expression array is a positively charged nylon membrane on which 588 mouse known cDNAs have been immobilized. These known genes have been reported to play key roles in many biological process and are characterized by tight transcriptional regulation, and represent many areas of current research including oncogenesis, cell cycle, apoptosis, signal transduction and immunological studies. Fig. 2 showed the gene expression profiles of NIH3T3 cells stably transfected with $C T 120$ and vector.
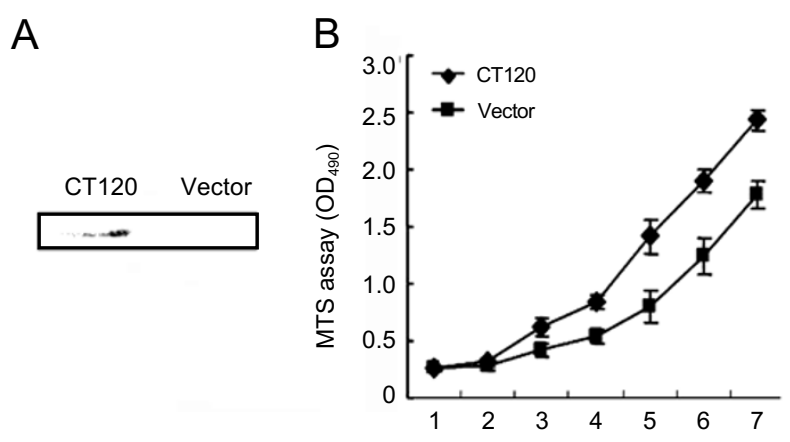

Fig. 1 Effect of CT120 ectopic expression on cell proliferation of NIH3T3 cells. NIH3T3 stable transfectants expressing CT120 were established by zeocin reagent selection. (A) The expression of Histagged CT120 in NIH3T3 cells was detected by Western blot with mouse anti-6xHisG monoclonal antibody (1:2000). (B) Cell proliferation activity assay of NIH3T3 cells stably transfected with CT120 and vector using MTS reagent. The cells were cultured for $6 \mathrm{~d}(1 \mathrm{~d}$ as a time point). Data were shown by mean \pm SD (vertical bars) of triplicate cultures and were representative of three experiments. MTS assays showed that CT120 expression remarkably increased the cell growth at the third day and persisted to the seventh day when compared with vector control $(P<0.01)$.

\section{Identification of altered gene patterns in response to $C T 120$ induction}

All the hybridization spots on the image were quantified and normalized against the internal control with QuantArray image analysis software. In the experiment, when the global gene expression profile of NIH3T3 stable transfectants expressing CT120 was compared to that of the empty vector transfected NIH3T3 cells, expression levels of 133 clones were altered in experimental cells. Among them, there are 97 clones whose expression is up-regulated (ratio $\geq 2.0$ ) and 36 clones down-regulated (ratio $\leq 0.5$ ). The differentially expressed genes and their induction fold are listed in Tab. 2 and Tab. 3. From the list of these altered 
A

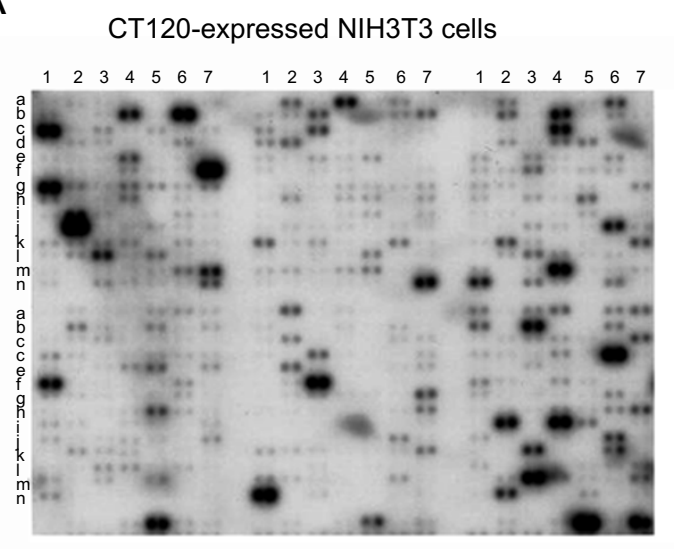

B

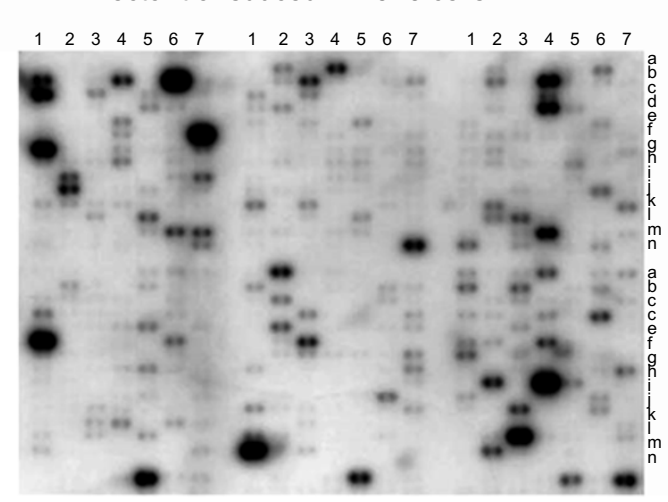

Fig. 2 Profiling gene expression of NIH3T3 cells induced by CT120 with ATLAS mouse cDNA expression arrays. (A) Gene expression profiles of NIH3T3 stable transfectants expressing CT120. The membrane was probed with ${ }^{32} \mathrm{P}-$ labeled cDNA prepared from NIH3T3 stable transfectants expressing CT120. (B) Gene expression profiles of empty vector transduced NIH3T3 cells. The membrane was probed with ${ }^{32} \mathrm{P}$-labelled cDNA prepared from empty vector transduced NIH3T3 cells.

genes, it is notable that many of the genes whose expression was affected by CT120 were key intracellular and extracellular signal transduction molecules, cell receptors and transcription factors. Two major signaling pathways involved in cell proliferation and anti-apoptosis were overexpressed in response to CT120: One of the major pathways upregulated was the Raf/MAPK signaling cascades. The expressions of 9 genes (Myc, $A$-Raf, $B$ Raf, Erk1, MAPK p38, MEK1, Rab 2, RASGF1, Crk) affecting this pathway were altered with overexpression of Myc, A-Raf, B-Raf, Erk, MAPK p38, MEK, Rab 2, $C r k$ and underexpression of RASGF1. The other major signaling pathway upregulated by CT120 in NIH3T3 cells was the PI3K/Akt signaling cascades and the expression of some important genes involved in Akt functions altered responsive to CT120 including oncogene $M D M 2,14-3-3$, $p 21^{\text {WAFI }}, p 27^{k i p 1}, M M P$, insulin-like growth factor $1 \mathrm{~A}$. In addition, some tumor metastasis associated genes cathepsins B, D, L and MMP-2/TIMP-2 were upregulated by CT120; moreover, CT120 might regulate the expressions of some candidate "Lung Tumor Progression" genes including B-Raf, Rab-2, BAX, BAG-1,YB-1, Cdc42, etc.

\section{Verification of the induced genes by quantitative RT-PCR}

To verify that the cDNA microarray data do, in fact, reflect changes in gene expression, we used quantitative RT-PCR techniques to confirm the findings for several genes that earned different induction folds. The selected genes were MEK1 (ratio $\geq 40$ ), PI3K (ratio $\geq 40$ ), Akt $($ ratio $=5.2)$ and integrin alpha $6($ ratio $=0.11)$. Fig. 3 showed the results of quantitative RT-PCR. These amplified products were quantitatively analyzed with densityscanning software. The results showed that the induction folds highly matched with that of cDNA microarray hybridization.

\section{Detection of PI3K, Akt1/2, phosphor-Akt and Erk1/} 2, phosphor-MEK1/2, phosphor-Erk1/2 in NIH3T3 stable transfectants expressing CT120

To further investigate the expressions at the translational level and determine the phosphorylation levels of MEK/Erk and PI3K/Akt in CT120-expressing NIH3T3 cells, the p-MEK1/2, Erk1/2 and p-Erk1/2, PI3K p $85 \alpha$, Akt1/2 and p-Akt1/2 were detected with anti-p-MEK1/2, anti-Erk1/2, anti-p-Erk1/2, anti-PI3K p85 $\alpha$, anti-Akt1/2,

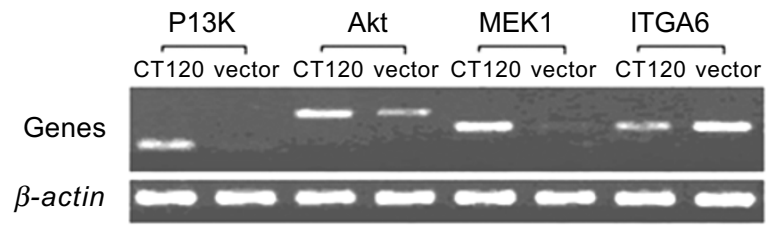

Fig. 3 Verification of microarray results with semi-quantitative RTPCR analysis. Four genes were selected from the genes that were differentially induced or suppressed by microarray hybridization. Based on the microarray hybridization results, PI3K was upregulated by CT120 at the ratio of > 50; Akt, 5.2; MEK1, > 50; ITGA6 was downregulated by CT120 as the ratio 0.11 . $\beta$-actin was amplified as an internal control. 
Tab. 2 Selected genes up-regulated by CT120

\begin{tabular}{|c|c|c|c|}
\hline Coordinate & $\begin{array}{l}\text { GenBank } \\
\text { No. }\end{array}$ & Gene name & $\begin{array}{l}\text { Induction } \\
\text { fold }\end{array}$ \\
\hline A1h & X58876 & $\begin{array}{l}\text { transformed mouse } 3 \mathrm{~T} 3 \text { cell double minute } 2(M d m) \text {; } \\
\text { p53-associated protein }\end{array}$ & $*$ \\
\hline A21 & X01023 & $m y c$ proto-oncogene & * \\
\hline $\mathrm{A} 3 \mathrm{k}$ & M13071 & A-raf proto-oncogene & * \\
\hline A31 & M64429 & $B$-raf proto-oncogene & 3.8 \\
\hline A6d & X66032 & G2/M-specific cyclin B2 (CCNB2; CYCB2) & 14.3 \\
\hline A6i & X75888 & G1/S-specific cyclin E1 (CCNE1) & 2.46 \\
\hline A6k & Z37110 & G2/M-specific cyclin G (ccng) & * \\
\hline A7f & U10440 & cyclin-dependent kinase inhibitor 1B (CDKN1B); p27 & 2.3 \\
\hline $\mathrm{A} 7 \mathrm{~g}$ & U20553 & $\begin{array}{l}\text { p57kip2;cdk-inhibitor kip2 (cyclin-dependent kinase } \\
\text { inhibitor } 1 B \text { ) }\end{array}$ & 5.06 \\
\hline $\mathrm{B} 4 \mathrm{~m}$ & S72408 & crk proto-oncogene & $*$ \\
\hline $\mathrm{B} 5 \mathrm{~h}$ & M61177 & $\begin{array}{l}\text { MAP kinase 3;MNK1; extracellular signal-regulated } \\
\text { kinase } 1(E R K 1) \text {; }\end{array}$ & 3 \\
\hline $\mathrm{B} 5 \mathrm{~m}$ & U10871 & $\begin{array}{l}\text { MAPK14;MAP kinase p38;CDC2-related kinase } 1 \\
(C R K 1)\end{array}$ & 21.4 \\
\hline B6a & L02526 & $\begin{array}{l}\text { MAP kinase kinase1;MAPKK1;MAP2K;MAPK/ERK } \\
\text { kinase } 1(M E K 1)\end{array}$ & $*$ \\
\hline B6k & M60651 & $\begin{array}{l}\text { phosphatidylinositol 3-kinase regulatory alpha subunit } \\
(P I 3 K P 85-\alpha)\end{array}$ & $*$ \\
\hline $\mathrm{B} 7 \mathrm{~b}$ & X95403 & ras-related protein $\mathrm{RAB} 2$ & 3.9 \\
\hline $\mathrm{C} 1 \mathrm{e}$ & U17162 & BCL-2-binding athanogene 1 (BAG1) & 8.8 \\
\hline $\mathrm{C} 1 \mathrm{f}$ & Y13231 & BCL-2homologous antagonist/killer $(B A K)$ & 6.8 \\
\hline $\mathrm{C} 1 \mathrm{~g}$ & L22472 & $\begin{array}{l}\text { BCL2-associated X protein membrane isoform alpha } \\
(B A X-\alpha)\end{array}$ & 11.6 \\
\hline $\mathrm{F} 2 \mathrm{n}$ & M14951 & insulin-like growth factor II (IGFII;IGF2); & 2.38 \\
\hline F3a & X04480 & insulin-like growth factor $1 \mathrm{~A}(I G F 1 A)$; somatomedin & 5.1 \\
\hline F6d & X51438 & Vimentin $(V I M)$ & 3.1 \\
\hline F6g & M14222 & cathepsin $\mathrm{B}(C T S B)$ & * \\
\hline F6h & X53337 & cathepsin $\mathrm{D}(C T S D)$ & * \\
\hline F6j & X06086 & cathepsin $\mathrm{L}(C T S L)$;major excreted protein $(M E P)$ & 7.2 \\
\hline F7c & X83536 & $\begin{array}{l}\text { MMP-14; membrae-type matrix metalloproteinase } 1 \\
(M T M M P 1)\end{array}$ & 37.9 \\
\hline F7m & X62622 & tissue inhibitor of metalloproteinase 2 (TIMP2) & 2.27 \\
\hline
\end{tabular}

*Genes induced by CT120 ( $\geq 50$-fold)

anti-p-S473 Akt and anti-p-Akt thr308 antibodies using immunoblotting and immunocytochemical assays. The results revealed that the protein expression of Erk1 increased slightly and the phosphorylation levels of MEK $1 / 2$ and Erk1 abundantly increased in NIH3T3 stable transfectants expressing CT120, compared to that in empty vector transduced NIH3T3 cells (Fig. 4 A, Fig. 5); The protein products of PI3K increased in CT120-expressing
NIH3T3 cells compared to that in empty vector transduced NIH3T3 cells. The Akt phosphorylation level at ser473 site increased remarkably, although the total of Akt protein had no remarkable difference between the CT120 expressing and empty vector transduced NIH3T3 cells. However, when deprived of serum in the medium, the expression and phosphorylation levels of PI3K and Akt showed no changes in response to CT120 (Fig. 4B, Fig. 6). 
Tab. 3 Selected genes down-regulated by CT120

\begin{tabular}{|c|c|c|c|}
\hline Coordinate & $\begin{array}{l}\text { GenBank } \\
\text { No. }\end{array}$ & Gene name & $\begin{array}{l}\text { Induction } \\
\text { fold }\end{array}$ \\
\hline $\mathrm{A} 1 \mathrm{~b}$ & U31625 & breast cancer protein $1(B R C A 1)$ & \\
\hline $\mathrm{A} 1 \mathrm{~g}$ & U58992 & SMAD-\&MAD-related protein $1(S M A D 1)$ & 0.29 \\
\hline A $1 \mathrm{k}$ & U36799 & $\begin{array}{l}\text { retinoblastoma-like protein } 2 \text {; retinoblastma-related } \\
\text { protein } \mathrm{RB} 2 / \mathrm{p} 130\end{array}$ & 0.21 \\
\hline $\mathrm{A} 5 \mathrm{~m}$ & X81580 & $\begin{array}{l}\text { insulin-like growth factor binding protein } 2 \text { (IGF-binding } \\
\text { protein2; } I G F B P 2)\end{array}$ & \\
\hline A6m & L01640 & $\begin{array}{l}\text { cyclin-dependent kinase } 4(C D K 4) \text {; cell division protein } \\
\text { kinase } 4\end{array}$ & 0.35 \\
\hline A7i & X59868 & $\begin{array}{l}\text { ras protein-specific guanine nucleotide-releasing factor } 1 \\
(R A S G F 1 ; G R F 1)\end{array}$ & \\
\hline $\mathrm{C} 21$ & L24495 & $\begin{array}{l}\text { tumor necrosis factor receptor superfamily member } 7 \\
\text { (TNFRSF7) }\end{array}$ & \\
\hline $\mathrm{C} 7 \mathrm{~m}$ & X74351 & $\begin{array}{l}\text { xeroderma pigmentosum group A complementing protein } \\
(X P A)\end{array}$ & 0.44 \\
\hline D41 & J03168 & interferon regulatory factor $2(I R F 2)$ & 0.36 \\
\hline D6f & M84819 & retinoic acid receptor gamma ( $R A R$ gamma; $R A R \gamma)$ & 0.214 \\
\hline E3g & M29697 & interleukin 7 receptor alpha (IL7R-alpha; $i l 7 r \alpha$ ) & \\
\hline E6c & M33158 & $\mathrm{CD} 3$ antigen zeta $(C D 3 Z)$ & 0.1 \\
\hline E7d & X69902 & integrin alpha $6(I T G A 6)$ & 0.11 \\
\hline F1g & U12983 & Cek 5 receptor protein tyrosine kinase ligand & 0.18 \\
\hline F2f & L38847 & hepatoma transmembrane kinas ligand & \\
\hline F4f & M13177 & transforming growth factor beta 1 (TGF-beta $1 ; T G F \beta 1$ ) & 0.34 \\
\hline F5g & U37720 & Cell division cycle 42 homolog ( $C D C 42)$ & \\
\hline
\end{tabular}

Genes repressed by CT120 ( $\geq 50$-fold)

\section{DISCUSSION}

Human novel gene CT120 was previously identified on chromosome $17 \mathrm{p} 13.3$, a hot region of mutation in several human malignancies including lung cancer. Previous studies showed that transcripts of CT120 were absent in human normal lung tissues, while was highly expressed in various tumor cell lines, among which human lung adenocarcinoma cell line A549 and SPC-A-1 cells expressed abundantly two transcripts of $C T 120$. Moreover, the mRNA of CT120 was abundant in most of human lung cancers. Overexpression of CT120 in A549 cells could promote the cell proliferation activity both in vitro and in vivo. The present study also showed that ectopic expression of CT120 in NIH3T3 cells could remarkably increase the cell growth in vitro. These findings suggested that CT120 might be a key modulator of cell proliferation involved in human lung carcinogenesis.

In this study, we have monitored the downstream effects of CT120 on NIH3T3 cells with mouse cDNA expression arrays. The results from the present study suggested that a group of genes were overexpressed or under-expressed in NIH3T3 cells in response to CT120 expression. Among the 588 mouse known genes, a total of 133 genes were up regulated and down regulated by CT120. Especially, about 61 genes that might be involved in extracellular, intracellular and transmembrane signaling pathways were differentially expressed in NIH3T3 stable transfectants expressing CT120. One of the major pathways up regulated was the Raf/MAPK signaling cascades. The expressions of 9 genes (Myc, A-Raf, B-Raf, Erkl, $M A P K$ p38, MEK1, RAB 2, RASGF1, crk) affecting this pathway were altered with over-expression of $M y c, A$ Raf, B-Raf, Erk, MAPK p38, MEK, RAB 2, crk and under-expression of $R A S G F 1$. Activation of the MEK/Erk pathway may contribute to tumorigenesis or cancer growth and activated Raf/MEK/Erk signaling pathway has been observed in many tumor cell lines and primary tumors [16]. Constitutive MEK/Erk activity was also 
A

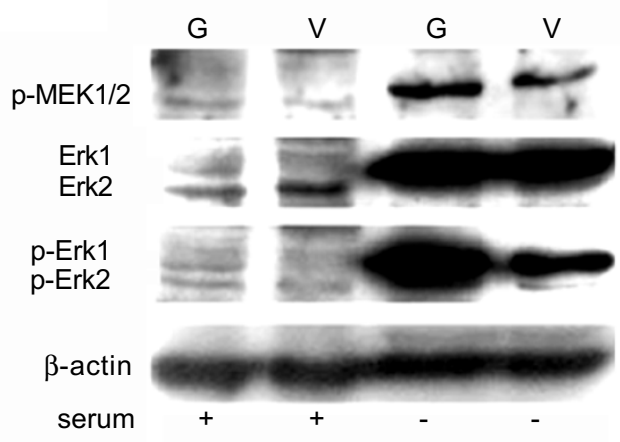

B

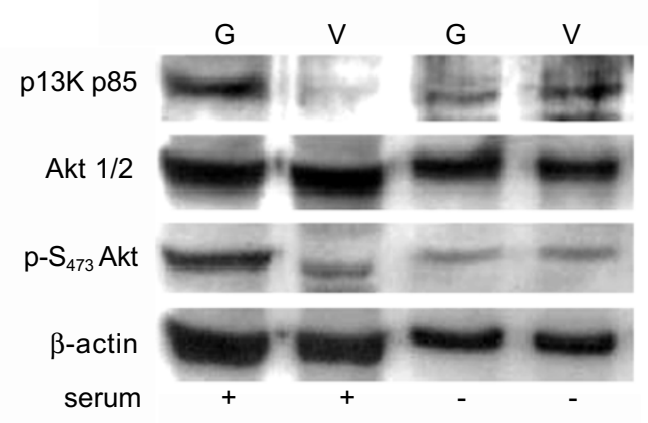

Fig. 4 Detection of the expression and phosporylation levels of MEK/Erk and PI3K/Akt in CT120-expressing NIH3T3 cells with immunoblotting analysis. The whole cell lysates from CT120-expressing and vector-transduced NIH3T3 cells were detected: (A) with anti-p-MEK1/2 (1: 500), anti-Erk1/2 (1:500), anti-p-Erk1/2 (1:500) antibodies, respectively; (B) with anti-PI3K p85 $\alpha$ (1:500), Akt1/2 (1:1000), p-Ser473 Akt (1:500) antibodies, respectively. $\beta$-actin was used as an internal control. "G" represents the CT120-expressing NIH3T3 cells; "V" represents empty vector transduced NIH3T3 cells. "+" showed the cells cultured in DMEM with serum; "-" showed the cells cultured in DMEM without serum.

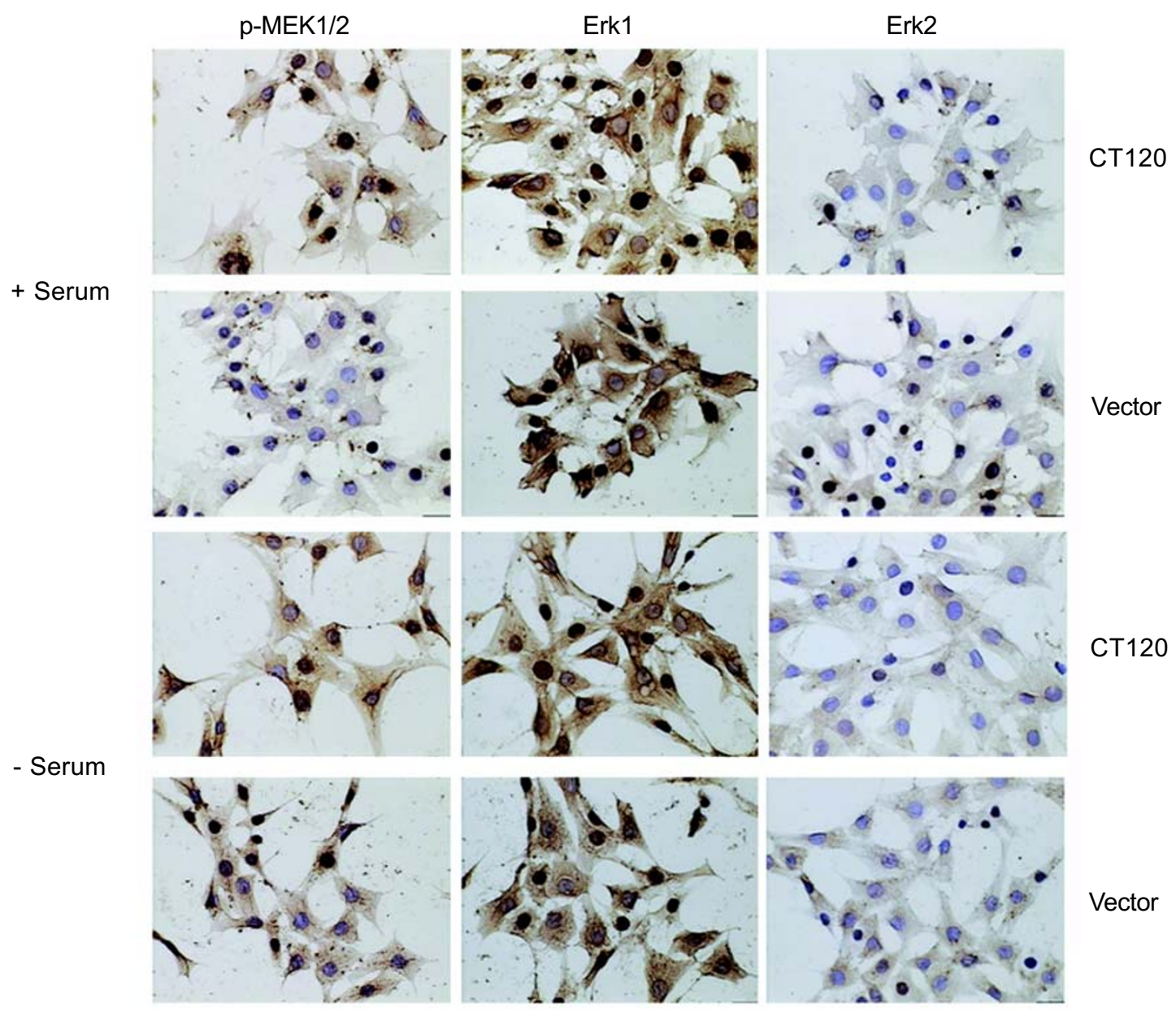

Fig. 5 Immunocytochemical staining of NIH3T3 cells transfected with $C T 120$ or vector with p-MEK1/2, p-Erk1/2 and Erk1/2. Serum factors can slightly promote the expression of Erk1, and obviously increase phosphorylation of MEK1/2 in CT120-transfected cells, but no evident effect on expression of Erk2 (top panels). Serum starvation can counteract these effects (bottom panels). Original magnification: $400 \times$. 


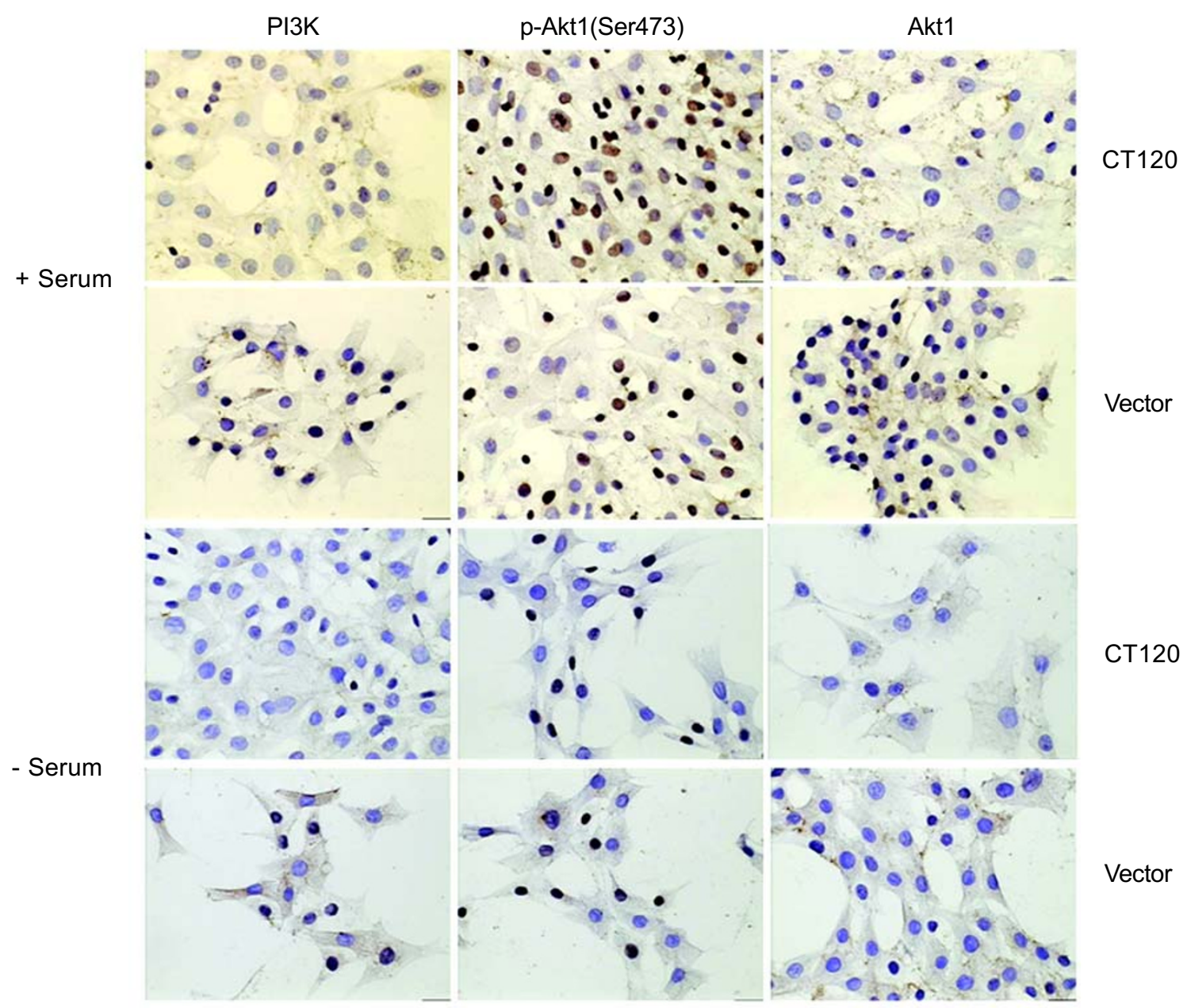

Fig. 6 Immunocytochemical staining of NIH3T3 cells transfected with CT120 or vector with PI3K, p-Akt1, Akt1 antibodies. Serum factors can slightly promote the expression of PI3K, obviously increase intranuclear phosphorylation of Akt1 at Ser473 in CT120-transfected cells, but no evident effect on expression of Akt1/2 (top panels). However, these effects were counteracted by serum starvation for $5 \mathrm{~h}$ (bottom panels). Original magnification: $400 \times$.

observed in lung cancer cell lines, which showed that constitutive Erk1/2 activity in NSCLC cells promotes cellular survival and chemotherapeutic resistance [17]. Constitutive Erk activity in 17/19 of NSCLC cell lines and Erk activity was increased in $8 / 21$ of lung cancer cell lines, most of which were small lung cancer cell lines. Erk activity did not correlate with NSCLC histology or mutation in $p 53, R b$ or $k$-Ras. But now, the mechanisms of increased Erk activity in NSCLC are unknown. From the present study, human novel gene CT120 overexpressed in most of primary lung cancer tissues and could slightly increase the expression and phosphorylation of MEK1/2, and could remarkably enhance expression and phosphorylation of Erk1, upon which we deduced that over-ex- pression of CT120 might contribute, at least in part, to constitutive Erk1/2 activity in lung tumor cell lines.

Another major signaling pathway up regulated and activated by CT120 in NIH3T3 cells was the PI3K/Akt signaling cascade, which plays a critical role in controlling the balance between survival and apoptosis. When activated, Akt can enhance cell proliferation and inhibits apoptosis by means of its ability to phosphorylate a host of substrate proteins involved in cell cycle progression, anti-apoptosis, cell proliferation and cell migration. Recent studies showed that Akt also plays a central role in tumorigenesis. Activation of Akt was found to be associated with the progression of some of human cancers [18]. In the present study, our results showed that PI3K and Akt was overexpressed 
in NIH3T3 cells by CT120, with the induction fold $>50$ and 5.2 respectively, as evidenced by cDNA microarray technology. The protein level of PI3K also increased abundantly. In addition, the phosphorylated of Akt at Ser473 site increased slightly as a result of CT120 transfection, while the total protein and phosphorylation levels of Akt at Thr308 did not show any evident difference between CT120-expressing and empty vector transduced NIH3T3 cells. Moreover, expression of some important genes involved in Akt functions was altered responsive to CT120, including oncogene MDM2, 14-3-3, p2 $1^{\text {WAF }}$, p27kip1, $M M P$, insulin-like growth factor $1 \mathrm{~A}$. Most strikingly, after serum deprivation, the expression and phosphorylation levels of PI3K and Akt showed no difference between CT120-transfected and empty vector transfected NIH3T3 cells. CT120 was previously identified as a novel plasma membrane protein with the property of $\mathrm{G}$ protein-coupled receptor bearing seven transmembrane regions (7-TM) (unpublished data). We hypothesized that maybe one or more components in serum could help CT120 in transducing the extracellular signals across plasma membrane. Activated CT120 further relay the signals through modulating the expressions and activities of different intracellular signaling pathways including Raf/MEK/Erk and PI3K/ Akt cascades.

In addition, over-expression of CT120 may be involved in tumor invasiveness and metastasis by regulating the expression of cathepsin proteases and MMP/TIMPs. High levels of several cathepsins have been associated with the pathological destruction of ECM, leading to tumor metastasis [19-21]. In this report, cathepsins B, L and D were overexpressed in NIH3T3 cells induced by CT120, which was in agreement with the report that the activities and protein levels of cathepsins B, D and L were induced in human lung tumors [22]. Matrix metalloproteinase-2 and its specific tissue inhibitor TIMP-2 also play important roles in lung cancer. Previous studies showed that MMPs and TIMPs were abundantly expressed in lung cancer tissues [23-25]. In this report, CT120 not only regulated expression of cathepsins but also that of MMPs and TIMPs in NIH3T3 cells, suggesting that overexpression of CT120 in human lung tumors might promote the invasiveness and metastasis of lung cancer cells, especially non small cell lung cancer cells.

Although the parallel gene expression analysis provides us a considerable view of the anti-apoptotic and cell survival gene expression programs invoked by CT120 in NIH3T3 cells, this study does not permit us to distinguish the direct targets of CT120 from the indirect ones. Resolving this issue and the complex interrelationships among the induced genes will require both alternative gene transfer technologies and other approaches, which are complementary to large-scale gene expression analysis.

\section{ACKNOWLEDGEMENTS}

We gratefully acknowledge Ms. YY ZHANG for her help in words processing. This work was supported by Major State Basic Research Development program of China (2004CB518704 and 2002CB513100).

Received, Sep 1, 2003

Revised, Jun 8, 2004

Accpeted, Jul 1, 2004

\section{REFERENCES}

1 Parkin DM, Bray F, Ferlay J, Pisani P. Estimating the world cancer burden: Globocan 2000. Int J Cancer 2001; 94:153-6

2 Testa JR, Liu Z, Feder M, et al. Advance in the analysis of chromosome alterations in human lung carcinomas. Cancer Genet Cytogenet 1997; 95:20-32.

3 Mertens F, Johansson B, Hoglund M, Mitelman F. Chromosome inbalance maps of malignant solid tumors: a cytogenetic survey of 3185 neoplasms. Cancer Res 1997; 57: 2765-80.

4 Rodenhuis S, Slebos RJ, Boot AJ, et al. Incidence and possible clinical significance of K-ras oncogene activation in adenocarcinoma of the human lung. Cancer Res 1988; 48:5738-41.

5 Harbour JW, Lai SL, Whang-Peng J, et al. Abnormalities in structure and expression of the human retinoblastoma gene in SCLC. Science 1988; 241:353-7.

6 Takahashi T, Nau MM, Chiba I, et al. p53: a frequent target for genetic abnormalities in lung cancer. Science 1989; 246:491-4.

7 Kamb A, Gruis NA, Weaver-Feldhaus J, et al. A cell cycle regulator potentially involved in genesis of many tumor types. Science 1994; 264:436-40.

$8 \mathrm{He} \mathrm{XH}, \mathrm{Di}$ YJ, Li JJ, et al. Molecular cloning and characterization of CT120, a novel membrane-associated gene involved in amino acid transport and glutathione metabolism. Biochem Biophys Res Commun 2002; 297:528-36.

$9 \mathrm{He}$ XH, Li JJ, Xie YH, et al. Expression of Human Novel Gene CT120 in Lung Cancer and Its Effects on Cell Growth. Ai Zheng 2003; 22:113-8 (In Chinese).

10 Tanaka H, Arakawa H, Yamaguchi T, et al. A ribonucleotide reductase gene involved in a p53-dependent cell-cycle checkpoint for DNA damage. Nature 2000; 404:42-9.

11 Yu J, Zhang L, Hwang PM, et al. Identification and classification of p53-regulated genes. Proc Natl Acad Sci USA 1999; 96: 14517-22.

12 Schena M, Shalon D, Davis RW, Brown PO. Quantitative monitoring of gene expression patterns with a complementary DNA microarray. Science 1995; 270: 467-70.

13 Khan J, Bittner ML, Saal LH, et al. cDNA microarrays detect activation of a myogenic transcription program by the PAX3FKHR fusion oncogene. Proc Natl Acad Sci USA 1999; 96: 13264-9.

14 Mullan PB, McWilliams S, Quinn J, et al. Uncovering BRCA1regulated signalling pathways by microarray-based expression profiling. Biochem Soc Trans 2001; 29: 678-83.

15 Jimenez AI, Fernandez P, Dominguez O, Dopazo A, SanchezCespedes M. Growth and molecular profile of lung cancer cells expressing ectopic LKB1: down-regulation of the phosphatidylinositol 3'-phosphate kinase/PTEN pathway. Cancer Res 
2003; 63: 1382-8.

16 Hoshino R, Chatani Y, Yamori T, et al. Constitutive activation of the 41-/43-kDa mitogen-activated protein kinase signaling pathway in human tumors. Oncogene 1999; 18:813-22.

17 Brognard J, Dennis PA. Variable apoptotic response of NSCLC cells to inhibition of the MEK/ERK pathway by small molecules or dominant negative mutants. Cell Death Differ 2002; 9: 893-904.

18 Testa JR, Bellacosa A.AKT plays a central role in tumorigenesis. Proc Natl Acad Sci USA 2001; 98:10983-5.

19 Duffy MJ. Proteases as prognostic markers in cancer. Clin Cancer Res 1996; 2:613-8.

20 Chapman HA, Riese RJ, Shi GP. Emerging roles for cysteine proteases in human biology. Annu Rev Physiol 1997; 59:63-88.
21 Krepela E, Prochazka J, Karova B, Cermak J, Roubkova H. Cysteine proteases and cysteine protease inhibitors in non-small cell lung cancer. Neoplasma 1998; 45:318-31.

22 Ledakis P, Tester WT, Rosenberg N, et al. Cathepsins D, B, and $\mathrm{L}$ in malignant human lung tissue. Clin Cancer Res 1996; 2:561-8.

23 Gonzalez-Avila G, Iturria C, Vadillo F, et al. 72-kD (MMP-2) and $92-\mathrm{kD}$ (MMP-9) type IV collagenase production and activity in different histologic types of lung cancer cells. Pathobiology 1998; 66:5-16.

24 Thomas P, Khokha R, Shepherd FA, Feld R, Tsao MS. Differential expression of matrix metalloproteinases and their inhibitors in non-small cell lung cancer. J Pathol 2000; 190:150-6.

25 Ohbayashi H. Matrix metalloproteinases in lung diseases. Curr Protein Pept Sci 2002; 3:409-21. 